\title{
A succinimide- $N$-sulfonic acid catalyst for acetylation reactions in absence of a solvent
}

\author{
Farhad SHIRINI*, Nader Ghaffari KHALIGH \\ Department of Chemistry, Faculty of Sciences, University of Guilan, Rasht, zip code 41335, Post box 1914, Iran
}

A R T I C L E I N F O

Article history:

Received 31 August 2012

Accepted 7 December 2012

Published 20 April 2013

Keywords:

Succinimde- $N$-sulfonic acid

Protection

Acetylation

Chemoselective reaction

Solvent-free condition

\begin{abstract}
A B S T R A C T
A small amount of succinimide- $N$-sulfonic acid efficiently catalyzed the acetylation of a variety alcohols, phenols, thiols, amines and aldehydes with acetic anhydride at room temperature under solvent free conditions. This catalyst has the advantages of excellent yields and short reaction times and the reaction can be carried out on a large scale, which makes it potentially useful for industrial applications.
\end{abstract}

(C) 2013, Dalian Institute of Chemical Physics, Chinese Academy of Sciences. Published by Elsevier B.V. All rights reserved.

\section{Introduction}

The protection of alcohols, phenols, thiols, and amines by the formation of esters and amides is one of the most important and widely used transformations in organic chemistry [1], especially with polyfunctional molecules such as nucleosides, carbohydrates, steroids, and natural products [2,3]. A variety of procedures are routinely used for the preparation of acetyl derivatives using homogeneous or heterogeneous catalysts such as 4-dimethylaminopyridine (DMAP) and 4-pyrolidinopyridine [4], tetramethylethylenediamine (TMEDA) [5], $\mathrm{Bu}_{3} \mathrm{P}$ [6], iodine [7], $p$-toluenesulfonic acid [8], alumina [9], zinc chloride [10], cobalt chloride [11], montmorillonit K-10 and KSF [12], zeolite HSZ-360 [13], zirconium sulfophenyl phosphonate [15], $\mathrm{Sc}(\mathrm{OTf})_{3}$ [15], $\mathrm{TaCl}_{5}$ [16], trimethylsilyl trifluoromethanesulfonate (TMSOTf) [17], Cu(OTf) 2 [18], In(OTf) 3 [19], magnesium bromide [20], bismuth(III) salts [21], ferric perchlorate adsorbed on silica-gel [22], $\mathrm{RuCl}_{3}$ [23], $\mathrm{InCl}_{3}$ [24], Ce(OTf) 3 [25], $\mathrm{Mg}\left(\mathrm{ClO}_{4}\right)_{2}$ [26], $\mathrm{ZrCl}_{4}$ [27], $\mathrm{Cp}_{2} \mathrm{ZrCl}_{2}$ [28], and cerium polyoxometalate [29]. However, each of these methods suffer from some disadvantages such as high temperature and drastic reaction conditions, formation of undesirable or toxic byproducts, expensive reagents, the reagents are hygroscopic or thermally unstable, use of halogenated solvents and strong acids, long reaction times or low yields of the desired products, and in most cases are only applicable to alcohols. Therefore, a new method and catalyst for the preparation of esters and amides is still in demand.

Acylals (1,1-diacetates) are remarkably stable derivatives of aldehydes that are widely used for the protection of compounds. They also have many applications in organic synthesis and industry. 1,1-Diacetates are useful precursors in asymmetric allylic alkylation [30], synthesis of natural products [31], and synthesis of 1-acetoxy dienes and 2,2-dichlorovinyl acetates for Diels-Alder reactions [32,33]. In addition, the acylal functionality can be converted to other functional groups by reaction with the appropriate nucleophiles $[34,35]$. In addition, 1,1-diacetates are used as cross-linking agents for the cellulose in cotton and as bleaching initiators in wine-stained fabrics [36,37]. Hence, methods for their synthesis have received con- 
siderable attention.

Usually the preparation of 1,1-diacetates are carried out by the reaction of aldehydes with acetic anhydride using catalysts such as $\mathrm{H}_{2} \mathrm{SO}_{4}$ [38], $\mathrm{H}_{3} \mathrm{PO}_{4}$ and $\mathrm{CH}_{3} \mathrm{SO}_{3} \mathrm{H}$ [33], $\mathrm{NH}_{2} \mathrm{SO}_{3} \mathrm{H}$ [39], $\mathrm{HClO}_{4}-\mathrm{SiO}_{4}$ [40], $\mathrm{Zr}\left(\mathrm{HSO}_{4}\right)_{4}$ [41], saccharin sulfonic acid [42], [Hmim] $\mathrm{HSO}_{4}$ [43], $p$-toluenesulfonic acid ( $p$-TSA) [44], silica-bonded S-sulfonic acid [45], silicasuloric acid [46], copper methanesulfonate-HOAc [47], 1,3-dibromo-5,5- dimethylhydantoin [48], $\mathrm{ZnCl}_{2}$ [49], $\mathrm{FeCl}_{3}$ [50], $\mathrm{PCl}_{3}$ [51], $\mathrm{InCl}_{3}$ [52], cyanuric chloride [53], ceric ammonium nitrate (CAN) [54], NBS [55], $\mathrm{WCl}_{6}$ [56], $\mathrm{SbCl}_{3}$ [57, 58], $\mathrm{ZrCl}_{4}$ [59], $\mathrm{LiClO}_{4}$ [60], Sc(OTf) 3 [61], Cu(OTf) 2 [62], Bi(OTf) 3 [63], LiOTf, [64], In(OTf) 3 [65], montmorillonite clay [66], expansive graphite [67], $\mathrm{H}_{3} \mathrm{PMo}_{12} \mathrm{O}_{40}$ [68], $\mathrm{H}_{6} \mathrm{P}_{2} \mathrm{~W}_{1} \mathrm{O}_{62} \cdot 24 \mathrm{H}_{2} \mathrm{O}$ [69], $\mathrm{AlPW}_{12} \mathrm{O}_{40}$ [70], zirconium sulfophenyl phosphonate [71] or $\mathrm{Bi}\left(\mathrm{NO}_{3}\right)_{3} \cdot 5 \mathrm{H}_{2} \mathrm{O}$ [72]. Although some of these catalysts can convert aldehydes to the corresponding diacetates with good to high yields, the majority suffer from at least one disadvantages such as prolonged reaction times, reaction under oxidizing conditions, use of a strong acid, low yields, harsh reaction conditions, difficulty in the preparation, moisture sensitivity of the reagent used, or high cost and high toxicity of the reagent used. Therefore, there is scope for developing an alternative method for the protection of aldehydes as acylals.

\section{Experimental}

\subsection{General}

All chemicals were purchased from Merck or Fluka Chemical Companies. All yields refer to the isolated products. Products were characterized by their physical constants and comparison with standard samples. The determination of the purity of the substrates and reaction monitoring were performed by TLC using silica gel SIL G/UV 254 plates. The MS were measured under $70 \mathrm{eV}$ conditions. The IR spectra were recorded on a Perkin Elmer 781 spectrophotometer. The ${ }^{1} \mathrm{H}$ NMR spectra were recorded with a Bruker Avance 400 or $300 \mathrm{MHz}$ instrument. Chemical shifts are reported in parts per million in $\mathrm{CDCl}_{3}$ with tetramethylsilane as an internal standard. ${ }^{13} \mathrm{C}$ NMR data were collected on a Bruker Avance 100 or $75 \mathrm{MHz}$ instrument. Melting points were recorded on a Büchi B-545 apparatus with open capillary tubes.

\subsection{Acetylation of alcohols, phenols, thiols, and amines with different amounts of succinimide $N$-sulfonic acid}

The substrate $(1.0 \mathrm{mmol})$ was treated with $\mathrm{Ac}_{2} \mathrm{O}(1.5-2$ $\mathrm{mmol}$ ) in the presence of succinimide $N$-sulfonic acid (SuSA, $0.028 \mathrm{mmol}$ ) at room temperature under solvent free conditions and with magnetic stirring. After the completion of the reaction as indicated by TLC, the mixture was diluted with $\mathrm{Et}_{2} \mathrm{O}$ $(25 \mathrm{ml})$ and the catalyst was allowed to settle down. The supernatant ethereal solution was decanted off, the catalyst washed with $\mathrm{Et}_{2} \mathrm{O}(2 \mathrm{ml})$ and the combined ethereal solution was concentrated under vacuum to afford the product. The product had identical physical properties (mp, IR, $1 \mathrm{H}$ and ${ }^{13} \mathrm{C}$
NMR, and GCMS) as a standard sample of the acetylated product. The recovered catalyst was dried at $50{ }^{\circ} \mathrm{C}$ under vacuum for $2 \mathrm{~h}$ and reused for four more acetylation reactions of benzyl alcohol (1.0 mmol) affording 98\%, 97\%, 97\%, and 96\% yields, respectively, in $2,3,3$, and $5 \mathrm{~min}$.

\subsection{Acetylation of alcohols, phenols, thiols, and amines with different substrates}

A mixture of $1 \mathrm{mmol}$ substrate, 2-3 mmol acetic anhydride, and $5 \mathrm{mg}$ SuSA ( $0.028 \mathrm{mmol}$ ) was stirred at room temperature in the absence of a solvent. The progress of the reaction was monitored by TLC. After completion of the reaction, the mixture was diluted with $15 \mathrm{ml}$ ethyl acetate and filtered. Then the solid residue was washed with $5 \mathrm{ml}$ ethyl acetate, then $5 \mathrm{ml}$ acetone and then dried. The recovered catalyst could be used for three more reaction runs. The organic layer was washed with $5 \mathrm{ml}$ of a saturated solution of $\mathrm{NaHCO}_{3}, 20 \mathrm{ml}$ brine and $20 \mathrm{ml}$ water, and dried over $\mathrm{MgSO}_{4}$. Evaporation of the solvent followed by column chromatography on silica gel followed by evaporation of the solvent gave the desired product in good to high yields.

\subsection{Spectral data of the selected products}

A (Table 2, entry 14): IR (neat, $\mathrm{cm}^{-1}$ ) 1738, 1697. ${ }^{1} \mathrm{H}$ NMR $\left(\mathrm{CDCl}_{3}, 400 \mathrm{MHz}\right): \delta 2.23(\mathrm{~s}, 3 \mathrm{H}), 6.84(\mathrm{~s}, 1 \mathrm{H}), 7.32-7.53(\mathrm{~m}$, $8 \mathrm{H}), 7.95(\mathrm{~d}, J=8.8 \mathrm{~Hz}, 2 \mathrm{H}) .{ }^{13} \mathrm{C} \mathrm{NMR}\left(\mathrm{CDCl}_{3}, 100 \mathrm{MHz}\right): \delta 20.1$, 77.2, 128.2, 128.3, 128.6, 128.8, 133.1, 133.1, 134.1, 169.9, 193.3.

B (Table 2, entry 16): IR (neat, $\mathrm{cm}^{-1}$ ) 1726; $[\alpha] 25=-38^{\circ}$ (neat). ${ }^{1} \mathrm{H} \mathrm{NMR}\left(\mathrm{CDCl}_{3}, 400 \mathrm{MHz}\right): \delta 0.82(\mathrm{~s}, 3 \mathrm{H}), 0.88(\mathrm{~s}, 3 \mathrm{H})$, $0.92(\mathrm{~s}, 3 \mathrm{H}), 1.26(\mathrm{~m}, 4 \mathrm{H}), 1.72(\mathrm{~m}, 2 \mathrm{H}), 2.08(\mathrm{~s}, 3 \mathrm{H}), 2.36(\mathrm{~m}$, $1 \mathrm{H}), 4.89(\mathrm{~d}, J=9.8 \mathrm{~Hz}, 1 \mathrm{H}) \cdot{ }^{13} \mathrm{C}\left(\mathrm{CDCl}_{3}, 100 \mathrm{MHz}\right): \delta 13.4,18.7$, 19.6, 21.2, 27.0, 28.0, 36.7, 44.8, 47.7, 48.6, 79.8, 171.3 .

C (Table 2, entry 19): $\mathrm{mp} 70-72{ }^{\circ} \mathrm{C}$; IR $\left(\mathrm{KBr}, \mathrm{cm}^{-1}\right) 1756 .{ }^{1} \mathrm{H}$ NMR ( $\left.\mathrm{CDCl}_{3}, 400 \mathrm{MHz}\right): \delta 2.38(\mathrm{~s}, 3 \mathrm{H}), 7.25(\mathrm{~d}, J=8.8 \mathrm{~Hz}, 1 \mathrm{H})$, $7.46(\mathrm{~m}, 2 \mathrm{H}), 7.55(\mathrm{~s}, 1 \mathrm{H}), 7.79(\mathrm{~m}, 3 \mathrm{H}) .{ }^{13} \mathrm{C} \mathrm{NMR}\left(\mathrm{CDCl}_{3}, 100\right.$ $\mathrm{MHz}): \delta 21.2,118.5,121.1,125.7,126.5,127.6,127.7,129.4$, 131.4, 133.7,148.3, 169.6.

D (Table 2, entry 23): IR (neat, $\left.\mathrm{cm}^{-1}\right)$ 1768. ${ }^{1} \mathrm{H} \mathrm{NMR}\left(\mathrm{CDCl}_{3}\right.$, $400 \mathrm{MHz}$ ): $\delta 2.31(\mathrm{~s}, 6 \mathrm{H}), 2.31(\mathrm{~s}, 3 \mathrm{H}), 7.14(\mathrm{~d}, J=8.0 \mathrm{~Hz}, 2 \mathrm{H})$,

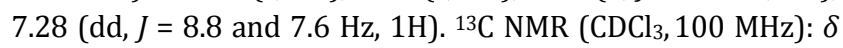
20.2, 20.7, 120.7, 125.9, 134.7, 143.6, 167.0, 167.9 .

E (Table 2, entry 28): IR (neat, $\mathrm{cm}^{-1}$ ) 3295, 1635. ${ }^{1} \mathrm{H}$ NMR $\left(\mathrm{CDCl}_{3}\right): \delta 2.30(\mathrm{~s}, 3 \mathrm{H}), 7.45-7.87(\mathrm{~m}, 8 \mathrm{H}) .{ }^{13} \mathrm{C} \mathrm{NMR}\left(\mathrm{CDCl}_{3}, 100\right.$ $\mathrm{MHz}$ ): $\delta$ 22.8, 118.5, 122.3, 122.8, 125.2, 126.1, 127.3, 127.8, $128.4,128.5,133.1,169.9$.

F (Table 2, entry 31): IR (neat, $\mathrm{cm}^{-1}$ ) 1743, 1653. ${ }^{1} \mathrm{H}$ NMR $\left(\mathrm{CDCl}_{3}, 400 \mathrm{MHz}\right): \delta 1.97(\mathrm{~s}, 3 \mathrm{H}), 2.02(\mathrm{~s}, 3 \mathrm{H}), 2.11(\mathrm{~s}, 3 \mathrm{H}), 2.20$ $(\mathrm{s}, 3 \mathrm{H}), 3.47(\mathrm{t}, J=6.0 \mathrm{~Hz}, 2 \mathrm{H}), 3.61(\mathrm{t}, J=5.6 \mathrm{~Hz}, 2 \mathrm{H}), 4.11(\mathrm{t}, J=$ $6.0 \mathrm{~Hz}, 2 \mathrm{H}), 4.19(\mathrm{t}, J=5.6 \mathrm{~Hz}, 2 \mathrm{H}), 4.59(\mathrm{~s}, 2 \mathrm{H}), 4.62(\mathrm{~s}, 2 \mathrm{H})$, 7.14-7.36 (m, 10H). ${ }^{13} \mathrm{C}$ NMR $\left(\mathrm{CDCl}_{3}, 100 \mathrm{MHz}\right): \delta$ 20.7, 20.8, 21.5, 21.6, 45.0, 46.1, 48.2, 53.1, 61.2, 62.2, 126.2, 127.5, 127.7, 127.9, 128.6, 128.9, 136.6, 137.2, 170.5, 170.8, 171.1, 171.5.

For this product (entry 31), a series of molecular $a b$ initio calculations were carried out to understand the ${ }^{1} \mathrm{H}$ and ${ }^{13} \mathrm{C}$ NMR spectra of 2-( $N$-benzylacetamido)ethyl acetate. Calcula- 
tions were performed with the Gaussian 98 set of programs [73] on a personal computer (Pentium 4). Geometry optimization were done both at the Hartree-Fock level with analytic gradients and with the $6-31 \mathrm{G}^{*}$ basis set. The results demonstrated that the product can exist in many conformations, and two conformations (I) and (II) were identified that had the lowest energy conformation. Figure 1 shows the result of rotation around the bond connecting the $\mathrm{C}_{1}-\mathrm{C}_{2}-\mathrm{N}_{3}-\mathrm{C}_{4}$ atoms. The conformational heterogeneity of this product and the high inter-conversion barriers are due to the high steric demand of the acetamide group with the ortho-position hydrogen atoms of the phenyl ring.

G (Table 2, entry 32): IR (neat, $\mathrm{cm}^{-1}$ ) 3320, 1730, 1682. ${ }^{1} \mathrm{H}$ NMR $\left(\mathrm{CDCl}_{3}, 400 \mathrm{MHz}\right): \delta 2.16(\mathrm{~s}, 3 \mathrm{H}), 2.36(\mathrm{~s}, 3 \mathrm{H}), 7.14-7.17$ (m, 2H), 7.22-7.25 (m, 1H), 7.39 (br s, $1 \mathrm{H}), 8.11$ (d, $J=7.6 \mathrm{~Hz}$, 1H). ${ }^{13} \mathrm{C} \mathrm{NMR}\left(\mathrm{CDCl}_{3}, 100 \mathrm{MHz}\right): \delta 20.6,22.7,117.8,120.7$, 123.9, 125.9, 130.7, 140.5, 167.0, 167.9.

H (Table 2, entry 35): IR (neat, $\mathrm{cm}^{-1}$ ) 1765, 1679. ${ }^{1} \mathrm{H}$ NMR $\left(\mathrm{CDCl}_{3}, 400 \mathrm{MHz}\right): \delta 2.33(\mathrm{~s}, 3 \mathrm{H}), 2.45(\mathrm{~s}, 3 \mathrm{H}), 7.24(\mathrm{~d}, J=8.0 \mathrm{~Hz}$, $1 \mathrm{H}), 7.33$ (t, J=7.6 Hz, 1H), 7.50 (t, J=7.6 Hz, 1H) 7.53 (d, $J=7.6$ $\mathrm{Hz}, 1 \mathrm{H}) .{ }^{13} \mathrm{C}$ NMR $\left(\mathrm{CDCl}_{3}, 100 \mathrm{MHz}\right): \delta 20.7,26.2,120.7,125.9$, 130.2, 134.7, 143.5, 167.0, 171.9 .

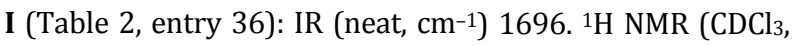
$400 \mathrm{MHz}$ ): $\delta 2.36(\mathrm{~s}, 3 \mathrm{H}), 4.29(\mathrm{~s}, 2 \mathrm{H}), 6.01(\mathrm{~d}, J=2.8 \mathrm{~Hz}, 1 \mathrm{H})$, $6.23(\mathrm{dd}, J=2.8$ and $0.8 \mathrm{~Hz}, 1 \mathrm{H}), 7.22(\mathrm{~d}, J=0.8,1 \mathrm{H}) .{ }^{13} \mathrm{C}$ NMR $\left(\mathrm{CDCl}_{3}, 100 \mathrm{MHz}\right): \delta 22.4,29.7,107.2,110.7,141.7,152.7,194.3$.

J (Table 5, entry 10): white solid, mp 65-67 ${ }^{\circ} \mathrm{C}$. IR (KBr, $\mathrm{cm}^{-1}$ ): 3650, 3500, 3010, 2910, 1760, 1610, 1590, 1490, 1430, $1370,1245,1200,1160,1060,1010,970,940,917,790,760$, 700, 670, 600. ${ }^{1} \mathrm{H}$ NMR (300 MHz, DMSO): $\delta 2.13$ (s, 6H, $2 \times$ $\mathrm{COCH}_{3}$ ), 3.38 (s, 3H, CH 3 ), 7.02 (d, 1H, J = 7.9 Hz, ArH), 7.50 (d, $1 \mathrm{H}, J=7.9 \mathrm{~Hz}, \mathrm{ArH}), 7.60-7.66(\mathrm{~m}, 2 \mathrm{H}, J=8.3, J=7.7 \mathrm{~Hz}, \mathrm{ArH})$, $147.74,135.42,133.82,127.94,125.12,123.53,87.83,21.93$, 21.00 .

K (Table 5, entry 15): white solid, mp $72-74{ }^{\circ} \mathrm{C}$. IR (neat, $\mathrm{cm}^{-1}$ ): 3035, 2985, 1760, 1610, 1595, 1530, 1465, 1370, 1310, $1245,1210,1170,1100,995,970,840,760 .{ }^{1} \mathrm{H} \mathrm{NMR}(300 \mathrm{MHz}$, $\left.\mathrm{CDCl}_{3}\right): \delta 2.10\left(\mathrm{~s}, 6 \mathrm{H}, 2 \times \mathrm{COCH}_{3}\right), 3.06\left(\mathrm{~s}, 3 \mathrm{H}, \mathrm{CH}_{3}\right), 3.89(\mathrm{~s}, 3 \mathrm{H}$, $\left.\mathrm{CH}_{3}\right), 6.81(\mathrm{~d}, 1 \mathrm{H}, J=4.9 \mathrm{~Hz}, \mathrm{ArH}), 6.88(\mathrm{dd}, 1 \mathrm{H}, J=4.9, J=1.1$ $\mathrm{Hz}, \mathrm{ArH}$ ), 6.98 (d, 1H, J = $1.1 \mathrm{~Hz}, \mathrm{ArH}), 7.97$ (s, 1H, CH(OAc)2). ${ }^{13} \mathrm{C}$ NMR (75 MHz, DMSO): $\delta 167.55,149.823,148.37,147.74$ $123.53,113.43,113.32,87.84,55.66,54.55,23.30$. 8.04 (s, 1H, CH(OAc)2). ${ }^{13} \mathrm{C}$ NMR (75 MHz, DMSO): $\delta$ 167.55,

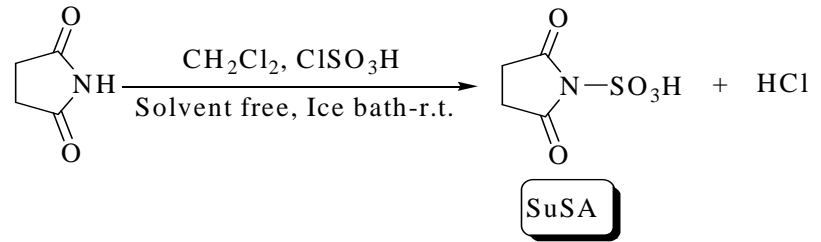

Scheme 1. Preparation of SuSA.

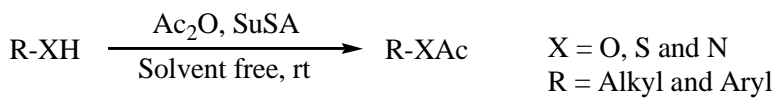

Scheme 2. Acetylation of alcohols, phenols, thiols, and amines catalyzed by SuSA.

L (Table 5, entry 24): white solid, mp 96-98 ${ }^{\circ} \mathrm{C}$. IR (KBr, $\mathrm{cm}^{-1}$ ): 3002, 2920, 1752, 1430, 1362, 1340, 1240, 1200, 1158, 1106, 1060, 1000, 942, 910, 808, 710, 680, 650, 600, 530, 510. 1H NMR (300 MHz, DMSO): $\delta 2.10\left(\mathrm{~s}, 12 \mathrm{H}, 4 \times \mathrm{COCH}_{3}\right), 7.52$ (d, $1 \mathrm{H}, J=7.8 \mathrm{~Hz}, \mathrm{ArH}), 8.00(\mathrm{~d}, 1 \mathrm{H}, J=7.9 \mathrm{~Hz}, \mathrm{ArH}), 8.17(\mathrm{~s}, 1 \mathrm{H}$, $\mathrm{CH}(\mathrm{OAc}) 2) .8 .43$ (dd, $2 \mathrm{H}, J=7.6, J=8.2 \mathrm{~Hz}, \mathrm{ArH}) .{ }^{13} \mathrm{C}$ NMR $(75$ MHz, DMSO): $\delta 167.00,141.19,129.62,128.82,126.32,102.33$, 22.55

M (Table 5, entry 15): white solid, mp 164-166 ${ }^{\circ} \mathrm{C}$. IR (KBr, $\mathrm{cm}^{-1}$ ): 3020, 2910, 1758, 1430, 1378, 1338, 1200, 1118, 1060, 1008, 960, 940, 910, 852, 818, 604, 580, 540. ${ }^{1} \mathrm{H}$ NMR $(300$ $\mathrm{MHz}_{\mathrm{CDCl}}$ ): $\delta 2.37\left(\mathrm{~s}, 6 \mathrm{H}, 2 \times \mathrm{COCH}_{3}\right), 7.29(\mathrm{~d}, 1 \mathrm{H}, J=5.7 \mathrm{~Hz}$, $\mathrm{ArH}), 7.41$ (d, 1H, J = 5.1 Hz, ArH), 8.26 (s, 1H, CH(OAc) $)_{2}{ }^{13} \mathrm{C}$ NMR (75 MHz, DMSO): $\delta 167.00,141.19,129.82,104.33,21.55$.

\section{Results and discussion}

Recently, we reported the preparation of succinimide- $N$-sulfonic acid (SuSA) (Scheme 1) and its application to the trimethylsilylation of hydroxyl groups and deprotection of the obtained trimethylsilyl ethers [74] and $N$-Boc protection of amines [75].

In a continuation of these studies, we investigated the applicability of this reagent as the catalyst for other organic functional group transformations. Our investigations clarified that SuSA can efficiently catalyze the acetylation of alcohols, phenols, amines, and thiols with $\mathrm{Ac}_{2} \mathrm{O}$ in the absence of a solvent (Scheme 2).
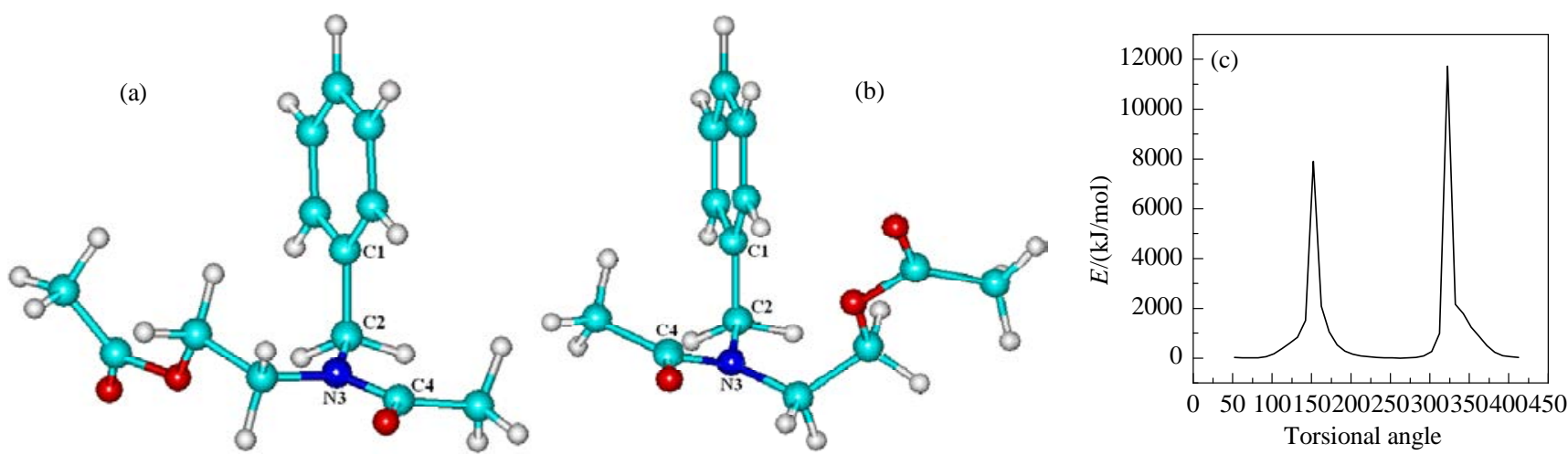

Fig. 1. Conformational energy $(\mathrm{kJ} / \mathrm{mol})$ for the lowest energy conformation of acetic acid 2-(acetyl-benzyl-amino)-ethyl ester as a function of rotation around the $\mathrm{C}_{1}-\mathrm{C}_{2}-\mathrm{N}_{3}-\mathrm{C}_{4}$ bond. 


\section{Table 1}

Reaction of benzyl alcohol and $\mathrm{Ac}_{2} \mathrm{O}$ in the presence of different amounts of SuSA at room temperature under solvent free conditions.

\begin{tabular}{lccc}
\hline Entry & Amount of SuSA (mol\%) & Time (min) & Yield ${ }^{\mathrm{a}}(\%)$ \\
\hline 1 & - & 720 & N.R. \\
2 & 1.1 & 5 & 76 \\
3 & 2.2 & 2 & 82 \\
4 & 2.8 & 2 & 98 \\
5 & 3.3 & 2 & 98 \\
6 & 4.4 & 2 & 98 \\
7 & 10 & 2 & 99 \\
\hline
\end{tabular}

Reaction conditions: $1.0 \mathrm{mmol}$ substrate, 1.5 equiv $\mathrm{Ac}_{2} \mathrm{O}$.

a Determined by GC-MS of the corresponding acetylated products.

In order to optimize the reaction conditions, different amounts of succinimide- $N$-sulfonic acid (SuSA) were used to make benzyl acetate from benzyl alcohol and acetic anhydride at room temperature under solvent free conditions. The results are summarized in Table 1 . The reaction can be carried out in the presence of small catalytic amounts of SuSA in the absence of a solvent, and the yields were excellent. It should be noted that when the reaction used a solvent, the reaction time became longer or the reaction did not proceed at all. The reaction did not occur in the absence of the catalyst (Table 1, entry 1).

After these preliminary experiments, a small catalytic amount of SuSA (2.8 mol\%) was used to convert a variety of functionalized alcohols and phenols with acetic anhydride into the corresponding esters and amides at room temperature under solvent free conditions. As shown in Table 2, different types of benzylic (including those with electron donating or withdrawing groups) and aliphatic alcohols underwent acetylation with $\mathrm{Ac}_{2} \mathrm{O}$ (1.5-2.0 equiv) in the presence of catalytic amounts of SuSA in the absence of a solvent at room temperature in good to high yields. The reaction conditions were mild enough not to induce any damage to moieties like the methoxy group (Table 2, entry 8), which often undergoes cleavage in the presence of strong acids or some Lewis acids. With sterically hindered alcohols, excellent chemoselectivity was observed as these compounds did not show any competitive dehydration (Table 2, entries 9-16). In order to show the mildness and stereospecificity of the SuSA catalyzed acetylation of alcohols, the reactions of optically active $\mathrm{L}(-)$-menthol and $\mathrm{R}(+)$-borneol were studied (Table 2, entries 12 and 16). We observed that $\mathrm{L}(-)$-menthol $\left([\alpha]_{\mathrm{D}}=-49.0^{\circ}, c=10\right.$ in 95\% ethanol, 99\% ee) and $\mathrm{R}(+)$-Borneol $\left([\alpha]_{\mathrm{D}}=+37.9^{\circ}, c=5\right.$ in ethanol, 99\% ee) reacted enantioselectively with the retention of the configuration on the benzylic center to provide L- $(-)$-Menthyl acetate $\left([\alpha]_{\mathrm{D}}=\right.$ $-73.0^{\circ}$, neat, $98 \%$ ee) and (+)-Bornyl acetate $\left([\alpha]_{\mathrm{D}}=+41.5^{\circ}\right.$, neat, $96 \%$ ee). The highest optical purity was obtained as an optically pure form in high yield and high regioselectivity by using SuSA at room temperature under solvent free conditions. The optical rotation of the product was determined and compared with that reported by Aldrich.

Our investigations showed that under the same reaction conditions, SuSA catalyzed the acetylation of phenols, amines, and thiols in good to high yields (Table 2, entries 17-36). Our protocol has the advantages that two or three groups were

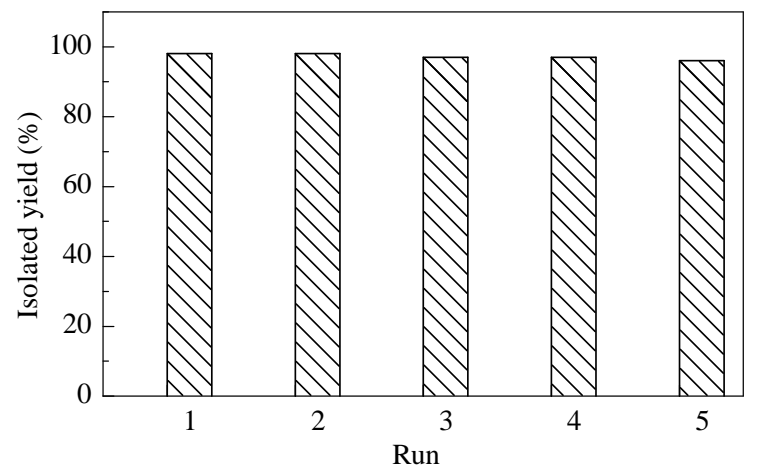

Fig. 2. Recovery and reuse of the catalyst for the acetylation of benzylalcohol with $\mathrm{Ac}_{2} \mathrm{O}$ at room temperature under solvent free conditions.

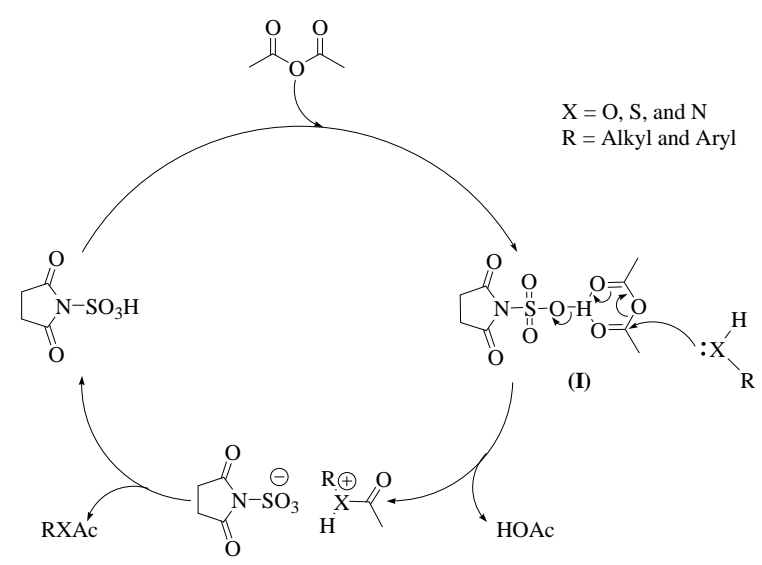

Scheme 3. Proposed mechanism of the acetylation of alcohols, phenols, thiols, and amines.

acetylated with the reaction conditions (Table 2, entries 20-23, 29-32, and 35) and furyl mercaptane was transformed smoothly to the corresponding acetate derivative (Table 2, entry 36).

SuSA was a reusable catalyst and after five runs of the acetylation of benzyl alcohol with acetic anhydride, the catalytic activity of SuSA was almost the same as that of the fresh cata-

Table 3

Superiority of SuSA catalyst for the acetylation of benzylalcohol over some recently reported catalysts at room temperature under solvent free conditions.

\begin{tabular}{|c|c|c|c|c|c|}
\hline Entry & Catalyst & $\begin{array}{l}\text { Amount of catalyst } \\
\text { (mol\%) }\end{array}$ & $\begin{array}{l}\text { Time } \\
\text { (min) }\end{array}$ & $\begin{array}{c}\text { Yield a }^{a} \\
(\%)\end{array}$ & Ref. \\
\hline 1 & $\mathrm{I}_{2}$ & 10 & 1 & 99 & [7] \\
\hline 2 & $\mathrm{CoCl}_{2}$ & 0.5 & 240 & 98 & [11] \\
\hline 3 & $\begin{array}{c}\text { montmorillonit } \\
\text { KSF }\end{array}$ & $20 \mathrm{mg}$ & 60 & 90 & [12] \\
\hline 4 & zeolite HSZ-360 & $20 \mathrm{mg}$ & 60 & 84 & [13] \\
\hline 5 & $\mathrm{Cu}(\mathrm{OTf})_{2}$ & 2 & 30 & 97 & [18] \\
\hline 6 & $\mathrm{RuCl}_{3}$ & 5 & 60 & 96 & [23] \\
\hline 7 & $\mathrm{InCl}_{3}$ & 0.1 & 30 & 85 & [24] \\
\hline 8 & $\mathrm{Ce}(\mathrm{OTf})_{3}$ & 1 & 12 & 98 & [25] \\
\hline 9 & $\mathrm{Mg}\left(\mathrm{ClO}_{4}\right)_{2}$ & 1 & 15 & 100 & [26] \\
\hline 10 & $\mathrm{Cp}_{2} \mathrm{ZrCl}_{2}$ & 1 & 600 & 93 & [28] \\
\hline 11 & SuSA & $2.8(5 \mathrm{mg})$ & 2 & 98 & this work \\
\hline
\end{tabular}


Table 2

SuSA catalyzed acetylation of alcohols, phenols, thiols, and amines with $\mathrm{Ac}_{2} \mathrm{O}$ at room temperature under solvent-free conditions.

\begin{tabular}{|c|c|c|c|c|c|c|c|c|c|}
\hline Entry & Substrate & Product & $\begin{array}{l}\text { Time } \\
\text { (min) }\end{array}$ & $\begin{array}{c}\text { Yield } \\
(\%)\end{array}$ & Entry & Substrate & Product & $\begin{array}{l}\text { Time } \\
\text { (min) }\end{array}$ & $\begin{array}{c}\text { Yield } \\
(\%)\end{array}$ \\
\hline 1 & & & 2 & 98 & 19 & & & 10 & 90 \\
\hline 2 & & & 2 & 96 & 20 & & & 30 & $84 \mathrm{~b}$ \\
\hline 3 & & & 2 & 95 & 21 & & & 20 & 87 b \\
\hline 4 & & & 2 & 94 & 22 & & & 2 & $93 \mathrm{~b}$ \\
\hline 5 & & & 30 & 88 & 23 & & & 35 & $92 \mathrm{c}$ \\
\hline 6 & & & 35 & 83 & 24 & & & 2 & 90 \\
\hline 7 & $C H$ & $-\mathrm{CH}$ & 2 & 94 & 25 & & & 1 & 96 \\
\hline 8 & & & 5 & 95 & 26 & & & 2 & 86 \\
\hline 9 & & & 4 & 92 & 27 & -1 & & 1 & 93 \\
\hline 10 & & & 4 & 92 & 28 & & & 2 & 90 \\
\hline 11 & & & 4 & 94 & 29 & & & 10 & $93 \mathrm{~b}$ \\
\hline 12 & & & 15 & 86 & 30 & & & 4 & $98^{\mathrm{b}}$ \\
\hline 13 & & & 8 & 88 & 31 & & & 10 & $98 \mathrm{~b}$ \\
\hline 14 & & & 10 & 96 & 32 & & & 2 & $98^{b}$ \\
\hline 15 & & & 10 & 89 & 33 & & & 10 & 92 \\
\hline 16 & & & 8 & 95 & 34 & & & 8 & 93 \\
\hline 17 & & & 10 & 94 & 35 & & & 20 & 90 \\
\hline 18 & & & 15 & 90 & 36 & & & 12 & 84 \\
\hline
\end{tabular}

a Isolated yield of acetylated product.

b Isolated yield of di-acetate.

c Isolated yield of tri-acetate.

lyst (Fig. 2).

To illustrate the efficiency of this catalyst, we compare the results of the acetylation of benzyl alcohol with acetic anhydride catalyzed by SuSA with some results reported in the literature (Table 3). It is clear that our reaction system is superior in terms of reaction time, catalyst amount, and product yield.

The probable mechanism is shown in Scheme 3. Acetic an- hydride is first activated by SuSA to afford (I). Alcohol, phenol, amine or thiol attacks I which in turn is converted to the final product and releases SuSA for the next catalytic cycle (Scheme 3).

The selectivity of this reaction system was checked with the competitive acetylation of benzyl alcohol, phenol, aniline, and thiophenol together. The results showed that aniline was acet- 
Table 4

Competitive acetylation of benzyl alcohol, phenol, thiophenol and aniline catalyzed by NSPVPC.

Entry

Reaction conditions: $1.0 \mathrm{mmol}$ substrate, 1.5 equiv $\mathrm{Ac}_{2} \mathrm{O}, 5 \mathrm{mg}(0.028 \mathrm{mmol})$ catalyst.

a Determined by GC-MS of the acetylated products.

ylated selectively in the presence of benzyl alcohol, phenol, and thiophenol (Table 4, entries 1 and 2). This can be considered as a useful practical achievement in the acetylation of amines in the presence of alcohols, phenols and thiols. Also, benzyl alcohol was acetylated selectively in the presence of phenol and thiophenol in 88\%:12\% and 85.6\%:14.4\% yields, respectively (Table 4, entries 3 and 4). Phenol was acetylated in the presence of thiophenol in 64:36\% yield (Table 4, entry 5).

Notably, the conversion of 4-chlorobenzyl alcohol to the acetate product can be carried out on a larger scale $(10 \mathrm{mmol})$ with $92 \%$ yield in $10 \mathrm{~min}$ by using $5 \mathrm{mg}$ ( $0.028 \mathrm{mmol})$ of SuSA. This indicates that a large scale reaction is possible with the same amount of the catalyst. It is important to point out that the present reaction system is clean, and does not need a chromatographic separation.

After the above study, we found that SuSA also efficiently catalyzed the conversion of aldehydes to their corresponding 1,1-diacetates with acetic anhydride (Scheme 4). The results are tabulated in Table 5.

As shown in Table 5, different types of aromatic aldehydes with different substituents such as $\mathrm{NO}_{2}, \mathrm{Cl}, \mathrm{Br}, \mathrm{CN}, \mathrm{Me}$, and $\mathrm{MeO}$ were converted to their corresponding acylals in good to high yields (Table 5, entries 1-15). In hydroxyl containing aromatic aldehydes, the phenol $-\mathrm{OH}$ groups were also acylated in high yields (Table 5, entries 16-18). Using this catalyst, furfural as an acid sensitive substrate was also protected in high yield and without the formation of any side products, which are normally

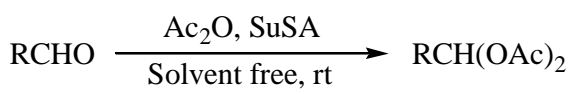

Scheme 4. Acetylation of aldehydes.

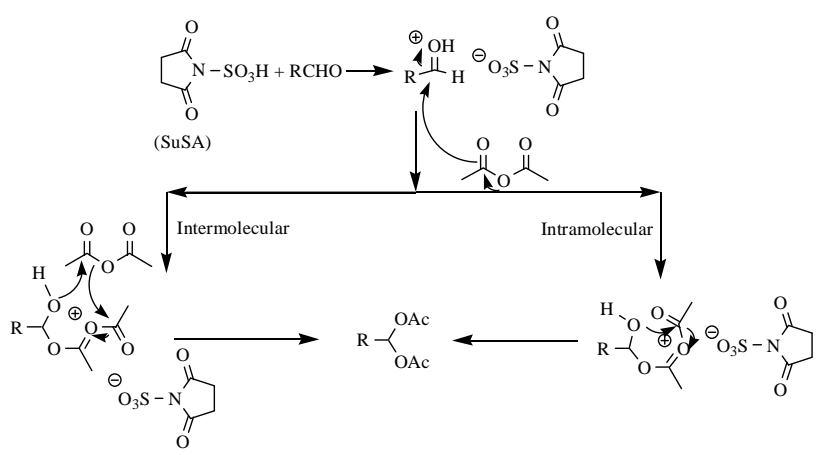

Scheme 5. Proposed mechanism of the acetylation of aldehydes.

formed under strongly acidic conditions (Table 5, entry 19). The catalyst is also very useful for the protection of aliphatic and $\alpha, \beta$-unsaturated aldehydes (Table 5, entries 20-22). No isomerisation of conjugated aldehydes was observed in the presence of SuSA. The acetylation of phthalaldehyde gave the diacetylated product in good yield (85\%) accompanied by a minor amount $(12 \%)$ of the tetraacylated product (Table 5 , entry 23). For iso-phthalaldehyde and tere-phethalaldehyde, the tetra-acylated products were obtained in high yields (Table

Table 6

Comparison of different catalysts in gem-diacetate synthesis from benzaldehyde and cinnamaldehyde.

\begin{tabular}{|c|c|c|c|c|}
\hline Entry & Catalyst & Time (min)/Yield (\%) ${ }^{a}$ & Time (min)/Yield (\%) b & Ref. \\
\hline 1 & succinimide sulfonic acid & $12 / 98$ & $5 / 93$ & this work \\
\hline 2 & saccharin sulfonic acid & $48 / 90$ & - & {$[14]$} \\
\hline 3 & $p$-TSA & $25 / 96$ & $35 / 92$ & {$[16]$} \\
\hline 4 & silica sulfuric acid & $30 / 84$ & $15 / 81$ & [18] \\
\hline 5 & copper methanesulfonate-HOAc & $78 / 94$ & $120 / 67$ & [19] \\
\hline 6 & 1,3-dibromo-5,5-dimethyl hydantoin & $90 / 98$ & $48 / 92$ & [20] \\
\hline 7 & NBS & $720 / 95$ & $1200 / 48$ & {$[27]$} \\
\hline 8 & {$[\mathrm{Hmim}] \mathrm{HSO}_{4}$} & $25 / 90$ & $10 / 95$ & [15] \\
\hline 9 & zirconium sulfophenyl phosphonate & $12 / 84$ & $180 / 72$ & [43] \\
\hline 10 & $\mathrm{Bi}\left(\mathrm{NO}_{3}\right)_{3} \cdot 5 \mathrm{H}_{2} \mathrm{O}$ & $90 / 87$ & $720 / 82$ & {$[44]$} \\
\hline
\end{tabular}

a Times and yields refer to gem-diacetate synthesis from benzaldehyde.

b Times and yields refer to gem-diacetate synthesis from cinnamaldehyde. 
Table 5

Acylation of aldehydes and deprotection of the obtained acylals a,b.

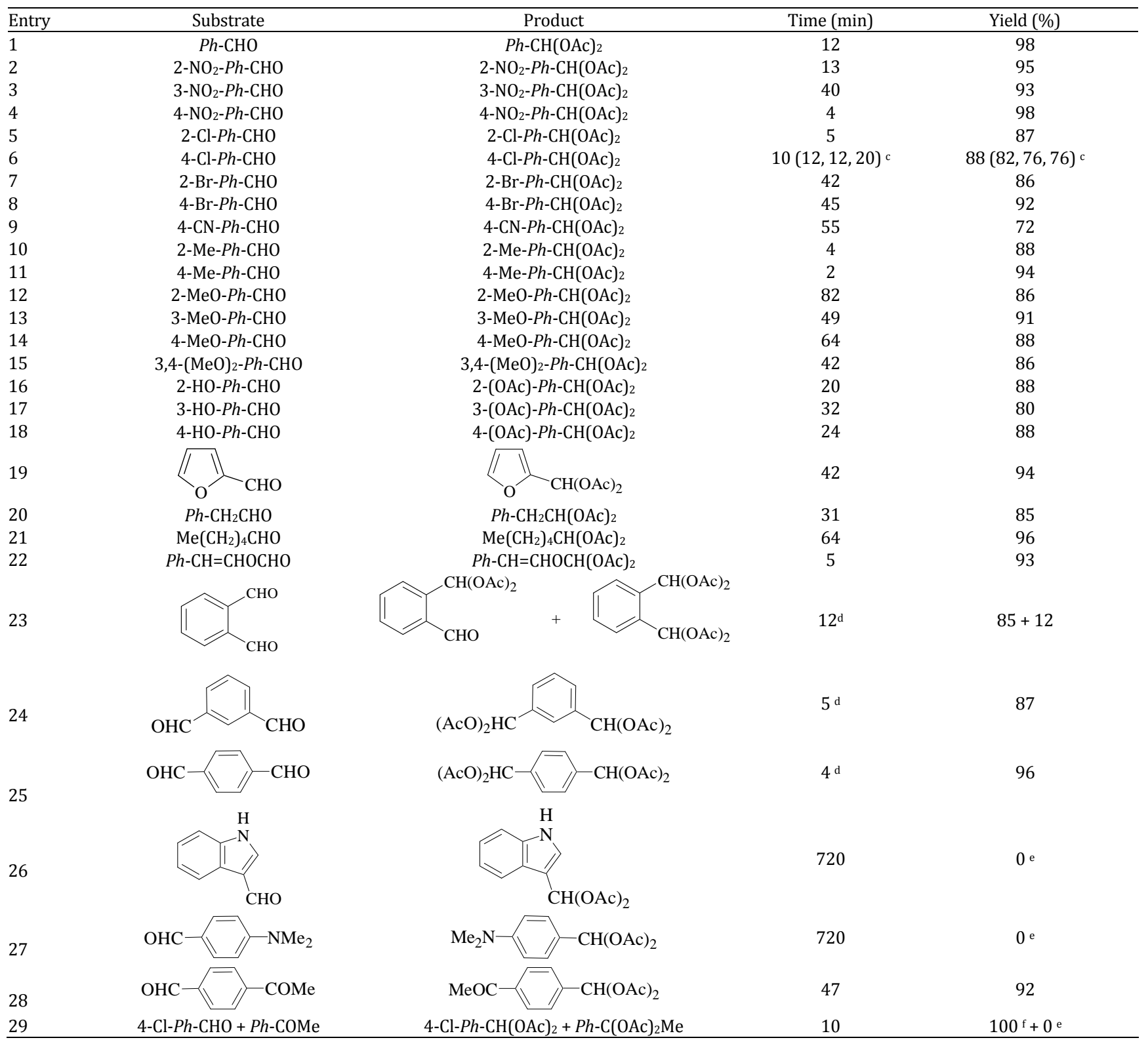

a Products were characterized by their physical properties and IR and NMR spectroscopy.

${ }^{b}$ Isolated yield. ${ }^{c}$ Results using recycled catalyst. ${ }^{\mathrm{d}} 3 \mathrm{mmol}$ of acetic anhydride was used. ${ }^{\mathrm{e}}$ Starting material recovered intact. ${ }^{\mathrm{f}}$ Conversion.

5, entries 24 and 25). However, 4-(dimethylamino) benzaldehyde and indole-3-carbaldehyde failed to give the corresponding 1,1-diacetates under the same conditions, which may be due to the electron donation ability of the dimethylamino and NH groups (Table 5, entries 26 and 27).

To evaluate the chemoselectivity of the catalyst, the competitive reactions for the acylation of aldehydes in the presence of ketones using SuSA as catalyst was also investigated. A highly selective conversion of aldehydes in the presence of ketones was observed (Table 5, entries 28 and 29).

In addition to economic benefits, a successful recycling of a catalyst will also lead to a cleaner process, because this will not leave any catalyst contamination in the products. We found that
SuSA can be effectively recovered from the reaction mixture during the work-up procedure (Table 5, entry 6). The percent of recovery in most cases was more than $80 \%$ and there was no change in the catalytic activity of SuSA.

As outlined in Scheme 5, the possible mechanism of this reaction may involve either intermolecular or intramolecular transfer of the second acetate group after the initial attack by acetic anhydride. The role of the catalyst here is the activation of the carbonyl group for these nucleophilic attacks.

In order to show the merit of the present work, Table 6 compares the results obtained from the gem acylation of benzaldehyde and cinnamaldehyde by our reaction system with some of those reported in the literature. 


\section{Conclusions}

The acetylation of alcohols, phenols, thiols, amines, and aldehydes with acetic anhydride are efficiently catalyzed by $\mathrm{Su}$ SA, which is a newly prepared succinimide-based reagent. High yields, short reaction times, mildness of the reaction conditions, ease of the preparation, stability and reusability of the reagent, chemoselectivity and easy work-up are the advantages of this catalytic reaction system.

\section{Acknowledgements}

We are thankful to the University of Guilan Research Council for the partial support of this work.

\section{References}

[1] Green T W, Wuts P G M. Protective Groups in Organic Synthesis. New York: Wiley. 1999

[2] Sun X L, Kai T, Takayanagi H, Furuhata K. Synlett, 1999: 1399

[3] Yadav J S, Narsaiah A V, Basak A K, Goud, P R, Sreenu D K, Nagaiah K. J Mol Catal A, 2006, 255: 78

[4] Scriven E F V. Chem Soc Rev, 1983, 12: 129

[5] Sano T, Ohashi K, Oriyama T. Synthesis, 1999: 1141

[6] Vedejs E, Bennett N S, Conn L M, Diver S T, Gingras M, Lin S, Oliver P A, Peterson M J. J Org Chem, 1993, 58: 7286

[7] Phukan P. Tetrahedron Lett, 2004, 45: 4785

[8] Cope A C, Herrich E C. Organic Synthesis Collective, Vol. IV. New York: Wiley, 1963. 304

[9] Breton G W, Kurtz M J, Kurtz S L. Tetrahedron Lett, 1997, 38: 3825

[10] Baker R H, Bordwell F G. Organic Synthesis Collective. Vol. III. New York: Wiley, 1995. 141

[11] Iqbal J, Srivastava R R. J Org Chem, 1992, 57: 2001

[12] Hagiwara H, Morohashi K, Suzuki T, Ando M, Yamamoto I, Kato M. Synth Commun, 1998, 28: 2001

[13] Ballini R, Bosica G, Carloni S, Ciaralli L, Maggi R, Sartori G. Tetrahedron Lett, 1998, 39: 6049

[14] Curini M, Epifano F, Marcotullio M C, Rosati O, Rossi M. Synth Commun, 2000, 30: 1319

[15] Ishihara K, Kubota M, Kurihara H, Yamamoto H. J Org Chem, 1996, 61: 4560

[16] Chandrasekhar S, Ramachander T, Takhi M. Tetrahedron Lett, 1998, 39: 3263

[17] Procopiou P A, Baugh S P D, Flack S S, Inglis G G A. J Org Chem, 1998, 63: 2342

[18] Saravanan P, Singh V K. Tetrahedron Lett, 1999, 40: 2611

[19] Chauhan K K, Frost C G, Love I, Waite D. Synlett, 1999: 1743

[20] Pansare S V, Malusare M G, Rai A N. Synth Commun, 2000, 30: 2587

[21] Mohammadpoor-Baltork I, Aliyan H, Khosropour A R. Tetrahedron, 2001, 57: 5851

[22] Parmar A, Kaur J, Goyal R, Kumar B, Kumar H. Synth Commun, 1998, 28: 2821

[23] De S K. Tetrahedron Lett, 2004, 45: 2919

[24] Chakraborti A K, Gulhane R. Tetrahedron Lett, 2003, 44: 6749

[25] Dalpozzo R, Nino A D, Maiuolo L, Procopiou A, Nardi M, Bartoli G, Romeo R. Tetrahedron Lett, 2003, 44: 5621

[26] Chakraborti A K, Sharma L, Gulhane R, Shivani. Tetrahedron, 2003, 59: 7661

[27] Chakraborti A K, Gulhane R. Synlett, 2004: 627
[28] Kantam M L, Aziz K, Likhar P R. Catal Commun, 2006, 7: 484

[29] Mirkhani V, Tangestani Nejad S, Moghaddam M, Yadollahi B, Alipanah L. Monatsh Chem, 2004, 135: 1257

[30] Trost B M, Lee C. J Am Chem Soc, 2001, 123: 12191

[31] Sandberg M, Sydnes L K. Org Lett, 2000, 2: 687

[32] Held H, Renestle A, Mayer A. Ullman's Encyclopedia of Industrial Chemistry, 5th Ed, Vol. 1. Gerhartz W ed. New York: Wiley-VCH, 1985

[33] Freeman F, Karchefski E M. J Chem Eng Data, 1977, 22: 355

[34] Van Heerden F R, Huyser J J, Bradley D, Williams G, Holzapfel C W. Tetrahedron Lett, 1988, 39: 5281

[35] Sandberg M, Sydnes L K. Tetrahedron Lett, 1988, 39: 6361

[36] Jr Frick J G, Jr Harper R J. J Apll Polym Sci, 1984, 29: 1433

[37] Sanderson W R. EP Patent 0125 781. 1984

[38] Wegscheider R, Spath E. Monatsh Chem, 1909, 30: 825

[39] Jin T S, Sun G, Li Y W, Li T S. Green Chem, 2002, 4: 255

[40] Kamble V T, Jamode V S, Joshi N S, Biradar A V, Deshmukh R Y. Tetraherdon Lett, 2006, 47: 5573

[41] Mirjalili B F, Zolfigol M A, Bamoniri A, Sheikhan N.J Chin Chem Soc, 2006, 53: 955

[42] Shirini F, Mamaghani M, Mostashari-Rad T, Abedini M. Bull Korean Chem Soc, 2010, 31: 2399

[43] Hajipour A R, Khazdooz L, Ruoho A E. Catal Commun, 2008, 9: 89

[44] Manjula K, Pasha M A. Synth Commun, 2007, 37: 1563

[45] Niknam K, Saberi D, Nouri Sefat M. Tetrahedron Lett, 2009, 50: 4058

[46] Desai U V, Thopta T S, Pore D M, Wadgaonkar P P. Catal Commun, 2006, 7: 508

[47] Wang M, Gong H, Jiang H, Wang Z. Synth Commun, 2006, 36: 1953

[48] Azarifar D, Ghasemnejad H, Ramzanian-lehmali F. Mendeleev Comuun, 2005, 15: 209

[49] Scriabine I. Bull Soc Chim Fr, 1961: 1194

[50] Wang C D, Li M H. Synth Commun, 2002, 32: 3469

[51] Michie J K, Miller J A. Synthesis, 1981: 824

[52] Yadav J S, Reddy B V S, Srinivas C. Synth Commun, 2002, 32: 1175

[53] Bandgar B P, Joshi N S, Kamble V T A. J Chin Chem Soc, 2007, 54: 489

[54] Roy S C, Banerjee B. Synlett, 2002: 1677

[55] Karimi B, Seradj H, Ebrahimian R. Synlett, 2000: 623

[56] Karimi B, Ebrahimian G R, Seradj H. Synth Commun, 2002, 32: 669

[57] Battacharya A K, Mujahid M, Natu A A. Synth Commun, 2008, 38: 128

[58] Xu R, Zhang J, Tian Y, Zhou J. J Iran Chem Soc, 2009, 6: 443

[59] Smith G, Reddy C S. Tetrahedron, 2003, 59: 9571

[60] Ziyaei A, Azizi N, Saidi M R. J Mol Catal A, 2005, 238: 138

[61] Aggarwal K K, Fonquerna S, Vennall G P. Synlett, 1998: 849

[62] Chandra K L, Saravanan P, Singh, V K. Synlett, 2000: 359

[63] Carrigan M D, Eash K J, Oswald M C, Mohan R S. Tetrahedron Lett, 2001, 42: 8133

[64] Karimi B, Maleki J.J Org Chem, 2003, 68: 4951

[65] Ghosh R, Maiti S, Chakraborty A, Halder R. J Mol Catal A, 2004, 215: 49

[66] Joshi M V, Narasimhan C S. J Catal, 1993, 141: 308

[67] Jin T S, Ma Y R, Zhang Z H, Li T S. Synth Commun, 1997, 27: 3379

[68] Heydari M M, Bakhtiari K, Bamoharram F F. Catal Commun, 2006, 7: 499

[69] Romanelli G P, Thomas H J, Barnoetti G T, Autino J C. Tetrahedron Lett, 2003, 44: 1301

[70] Firouzabadi H, Iranpoor N, Nowrouzi F, Amani K. Tetrahedron Lett, 2003, 44: 3951

[71] Curini M, Epifano M, Marcotullio M C, Rosati O, Nocchetti M. Tetrahedron Lett, 2002, 43: 2709 


\section{Graphical Abstract}

Chin. J. Catal., 2013, 34: 695-703 doi: 10.1016/S1872-2067(11)60499-3

\section{A succinimide- $\mathrm{N}$-sulfonic acid catalyst for acetylation reactions in absence of a solvent}

Farhad SHIRINI*, Nader Ghaffari KHALIGH

University of Guilan, Iran

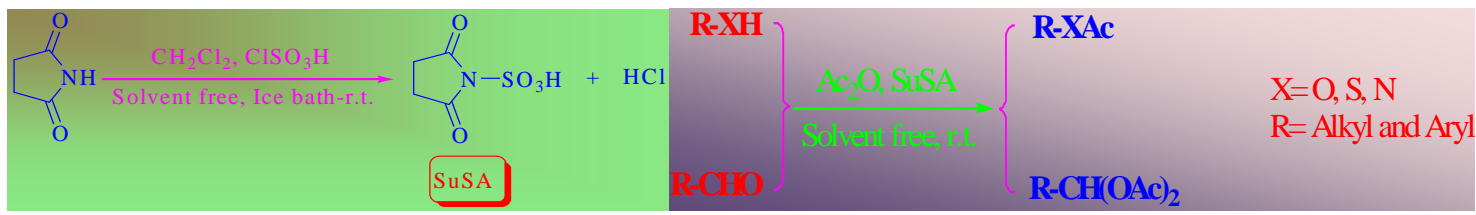

Succinimide- $N$-sulfonic acid was prepared by a simple route and shown to be an efficient catalyst for the acetylation of a variety alcohols, phenols, thiols, amines, and aldehydes with acetic anhydride at room temperature under solvent free conditions.

[72] Aggen D H, Arnold J N, Hayes P D, Smoter N J, Mohan R S. Tetrahedron, 2004, 60: 3675

[73] Frisch M J, Trucks G W, Schlegel H B, Scuseria G E, Robb M A, Cheeseman J R, Zakrzewski V G, Montgomery Jr, J A, Stratmann R E, Burant J C, Dapprich S, Millam J M, Daniels A D, Kudin K N, Strain M C, Farkas O, Tomasi J, Barone V, Cossi M, Cammi R, Mennucci B, Pomelli C, Adamo C, Clifford S, Ochterski J, Petersson G A, Ayala P Y, Cui Q, Morokuma K, Malick D K, Rabuck A D, Raghavachari K, Foresman J B, Cioslowski J, Ortiz J V, Baboul
A G, Stefanov B B, Liu G, Liashenko A, Piskorz P, Komaromi I, Gomperts R, Martin R L, Fox D J, Keith T, Al-Laham M A, Peng C Y, Nanayakkara A, Gonzalez C, Challacombe M, Gill P M W, Johnson B, Chen W, Wong M W, Andres J L, Gonzalez C, Head-Gordon M, Replogle E S, Pople, J A. Gaussian 98, revision A7, Gaussian, Inc, Pittsburgh PA, 1998

[74] Shirini F, Khaligh N G. Phosphorus Sulfur Silicon, 2011, 186: 2156

[75] Shirini F, Khaligh, N G. Monatsh Chem, 2012, 143: 631 